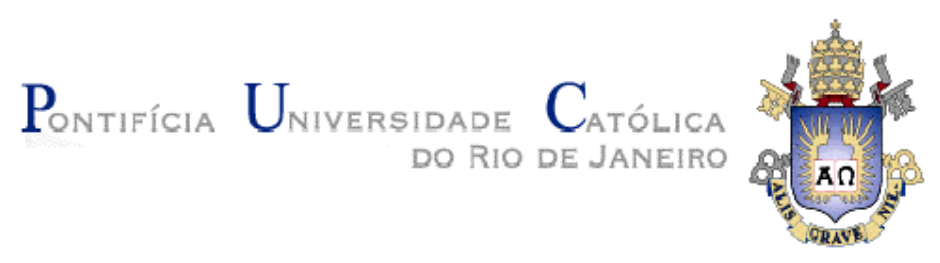

Ângela Silva de Sousa

\title{
A Lei 10.639/03 no Ensino Fundamental: um estudo de caso em Nova Iguaçu/RJ
}

Dissertação de Mestrado

Dissertação apresentada como requisito parcial para obtenção do grau de Mestre pelo Programa de PósGraduação em Educação do Departamento de Educação da PUC-Rio.

Orientadora: Prof ${ }^{a}$ Vera Maria Ferrão Candau

Rio de Janeiro Março de 2016 


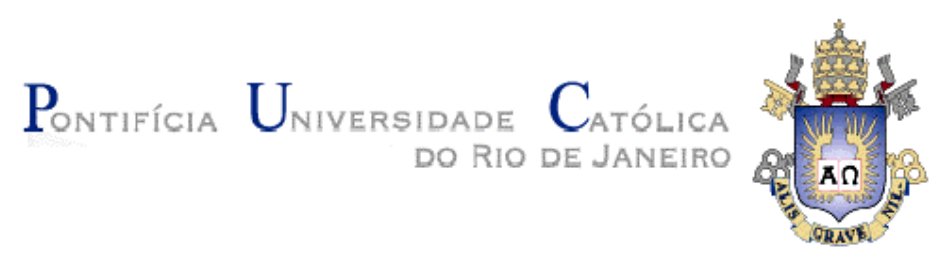

Ângela Silva de Sousa

\section{A Lei 10.639/03 no Ensino Fundamental: um estudo de caso em Nova Iguaçu/RJ}

Dissertação apresentada como requisito parcial para obtenção do grau de Mestre pelo Programa de PósGraduação em Educação do Departamento de Educação do Centro de Teologia e Ciências Humanas da PUC-Rio. Aprovada pela Comissão Examinadora abaixo assinada.

Profa . Vera Maria Ferrão Candau

Orientadora

Departamento de Educação - PUC-Rio

Prof. Marcelo Gustavo Andrade de Souza Departamento de Educação - PUC-Rio

Profa. Daniela Frida Drelich Valentim

UERJ

Prof ${ }^{a}$ Denise Berruezo Portinari Coordenadora Setorial do Centro de Teologia e Ciências Humanas

PUC-Rio

Rio de Janeiro, 30 de março de 2016 
Todos os direitos reservados. É proibida a reprodução total ou parcial do trabalho sem autorização da universidade, da autora e do orientador.

\section{Ângela Silva de Sousa}

Graduada em Pedagogia pela Pontifícia Universidade Católica do Rio de Janeiro (PUC-Rio) e Professora do Ensino Básico do Município do Rio de Janeiro.

Ficha Catalográfica

Sousa, Ângela Silva de

A Lei 10.639/03 no Ensino Fundamental : um estudo de caso em Nova Iguaçu/RJ / Ângela Silva de Sousa ; orientadora: Vera Maria Ferrão Candau. - 2016.

$163 \mathrm{f.} ; 30 \mathrm{~cm}$

Dissertação (mestrado)-Pontifícia Universidade Católica do Rio de Janeiro, Departamento de Educação, 2016.

Inclui bibliografia

1. Educação - Teses. 2. Educação. 3. Escola. 4. Interculturalidade. 5. Relações étnico-raciais. 6. Lei 10.639/09. I. Candau, Vera Maria Ferrão. II. Pontifícia Universidade Católica do Rio de Janeiro. Departamento de Educação. III. Título.

CDD: 370 
Dedico este trabalho aos meus pais que me criaram com todo amor e comprometimento, mesmo diante das inúmeras dificuldades. 


\section{Agradecimentos}

À Deus em primeiro lugar, por ter me acompanhado em todos os momentos da vida, que nem sempre foram fáceis, mas sempre superados em virtude de sua presença.

Á minha querida mãe, por seu amor e apoio incondicional. Por cuidar dos meus filhos com toda a dedicação.

Ao meu pai que sempre sonhou com um futuro diferente para seus filhos e da sua maneira, sempre buscou formas de possibilitar isso.

Ao meu marido, amigo e companheiro, Acácio Bergamini, que esteve ao meu lado pacientemente nesse processo árduo e difícil processo da construção da dissertação.

Ao meu irmão Alex. Obrigada por sempre estar ao meu lado e acreditar em mim, muitas vezes até mais do que eu mesma! Se estou aqui hoje, agradeço, entre outras pessoas, a você!

Á minha irmã Alessandra, que sempre acalmou meu coração com suas doces palavras repletas do amor de Deus.

Aos meus amados filhos, Guilherme e a Luana, que me ensinaram a amar incondicionalmente, a perceber a importância de olhar atentamente o "Outro" e dar um verdadeiro sentido à tudo o que faço nessa vida.

À minha querida orientadora, Vera Maria Candau, que me acompanha desde a graduação tecendo considerações pertinentes e me ensinando a ser mais humana em meus propósitos profissionais. 
Ao GECEC, que me proporcionou reflexões fundamentais para a construção dessa dissertação e para a vida.

Aos membros da banca, professor Marcelo Andrade e Daniela Valentim. Obrigada pelo aceite e ricas contribuições ao trabalho.

Ao CNPq que através da bolsa de estudos propiciou maior dedicação aos meus estudos.

Aos amigos e amigas da turma de mestrado, que dividiram todas as angústias, medos e alegrias comigo durante esses dois anos, Roberta Pitta, Carolynna Barroca, Rômulo Casciano, Érica Lins, Élio Portela, Jéssica Castro, Dimas Martorello, Joycimar Barcellos, Rosa Pires, João Paulo Cabrera, Carla Maria, Cintia Costa, Liliane Albuquerque, Elisa Motta, Carolina Kiu, Renata Nascimento e Calu Silveira.

Às flores que vivem a perfumar meu caminhar: Edileia Carvalho, Patrícia Sodré.

Aos amigos, companheiros e irmãos de todos os momentos, àqueles que me amam tanto que eu chego a sentir de longe, Letícia Martins, Fabrícia Lins, Vander de Melo, Jaqueline Braz e Yannick Bonthonneau.

Á minha amiga e comadre Joice Guedes, pela presença na distância, pelo laço eterno e companheirismo sem igual. Te amo!

Àquelas que me ensinaram muito sobre a arte de ser professora, que me encantaram de forma a nunca serem esquecidas, Thaís Alves, Alfa Gonçalves, Jaqueline Braz, Nubia Ribeiro, Amanda e Cristina Freire. Obrigada!!! 


\section{Resumo}

Sousa, Ângela da Silva; Candau, Vera Maria Ferrão. A Lei 10.639/03 no Ensino Fundamental: um estudo de caso no município de Nova Iguaçu. Rio de Janeiro, 2016. 163 p. Dissertação de Mestrado - Departamento de Educação, Pontifícia Universidade Católica do Rio de Janeiro.

A presente dissertação tem como objetivo compreender como se dão as práticas pedagógicas baseadas na implementação da Lei 10.639/03 em uma escola pública do município de Nova Iguaçu. O referencial teórico que embasou as discussões foram os estudos sobre relações étnico raciais, educação escolar e cultura(s), focando na Educação Intercultural. Baseia-se em um estudo de caso de caráter qualitativo. As estratégias metodológicas utilizadas foram: análise de documentos (Projeto Político Pedagógico da escola e textos legais que dão suporte a Lei $10.639 / 03$ ), observações de atividades pedagógicas no período de cinco meses (março a julho) no ano de 2015 e entrevistas semi-estruturadas com 10 membros da equipe pedagógica, sendo 7 professoras e 3 gestoras. A partir da análise de dados percebemos que a implementação da Lei 10.639/03 apresenta limites e possibilidades. Livros de literatura infanto-juvenil permeados pela temática africana e afro-brasileira, sobretudo quando apresentam personagens negros evidenciam caminhos para se trabalhar a temática étnico-racial na escola, especialmente no que concerne à construção da identidade racial dos/das alunos/as. Os recursos materiais, a religiosidade e a formação/concepção de professores/as são questões levantadas enquanto limites, embora apresentem saídas à configuração de novos processos pedagógicos, novas maneiras de se pensar a prática . Em suma, a escola pesquisada inclui no seu dia-a-dia atividades e conteúdos sobre a temática contida no corpo da Lei 10.639/03 e suas diretrizes curriculares. Apresenta em seu Projeto Político Pedagógico a temática racial, embora não como um tema central. Apesar de as práticas pedagógicas/culturais realizadas na escola privilegiarem a construção identitária das crianças, numa perspectiva de percepção de suas identidades, o que consideramos muito importantes, é possível perceber esforços e avanços no que se refere ao aprofundamento das relações com os demais grupos sociais, vislumbrando passos em direção ao que nomeamos de Educação Intercultural.

\section{Palavras-chave:}

Educação; Escola; Interculturalidade; Relações étnico-raciais; Lei 10.639/09; identidade; diferença. 


\section{Abstract}

Sousa, Ângela Silva; Candau, Vera Maria Ferrão. (Advisor) (The 10.639/03 Act on primary school: a case study in the city of Nova Iguaçu). Rio de Janeiro, 2016. 163 p. MSc. Dissertation - Departamento de Educação, Pontifícia Universidade Católica do Rio de Janeiro.

The aim of the present dissertation is to understand the pedagogical practices that stem from the implementation of the 10.639/03 Act at a public school of Nova Iguaçu. The theoretical background to the discussion gathers studies on racial and ethnic relations, school and culture, focusing on Intercultural Education. It is based on a qualitative case study. The methodological methods involved are: document analysis (Political Pedagogical Project of the school, and legal texts supporting the 10.639/03 Act), observations of pedagogical activities during five months (march to july) in 2015, semi-structured interviews with 10 members of the pedagogical team, including 7 teachers and 3 staff. From the data analysis, we observed that the implementation of the 10.639/03 Act both has its limits and opens new possibilities. Books from the juvenile litterature infused with african and afro-brasilian themes, in particular when they present black characters, illustrate means to work on racial and ethnics theme in school, in particular regarding the construction of the racial identity of the students. The teaching resources, the religiosity, the formation of teachers and their conceptions are all seen to be part of the limitations, but they are also the key to new pedagogical processes, new ways to think the practice of pedagogy. In a nutshell, the school that we studied daily includes activities and contents following the themes present in the body of the 10.639/03 Act and its curricular guidelines. It features the Race issue in its Political Pedagogical Project, albeit not as a central theme. Although the pedagogical/cultural practices in the school are focused on the construction of the identity of the children, in the perspective of self-perception of their own identity, that we find paramount, it is also possible to perceive efforts and advances in the direction of better relations between social groups, giving a glimpse of what we could call a truly Intercultural Education.

\section{Key-words:}

Education, School, Interculturality, Ethnic and racial relations, 10.639/03 Act, Identity, Difference. 


\section{Sumário}

1 Introdução................................................................. 13

1.1 A construção do objeto ................................................. 17

1.2 Revisão bibliográfica ............................................................ 22

1.3 Justificativa e relevância do estudo ..................................... 28

1.4 Problemática, objetivos e questões orientadoras do trabalho . 30

$1.5 \quad$ Estrutura da dissertação ..................................................... 32

2 Relações étnico raciais e educação escolar: processos históricos e políticos .......................................................... 33

2.1 A Lei 10.639/03: uma política de ação afirmativa ................... 33

2.2 Documentos oficiais que subsidiam a Lei - O que dizem? ..... 43

2.2.1 Conferência de Durban ...................................................... 44

2.2.2 Diretrizes Curriculares Nacionais para as Relações Étnico Raciais e para o Ensino da História e Cultura Afro-Brasileira

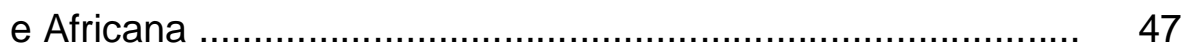

2.2.3 Plano Nacional de Implementação das Diretrizes Nacionais para a Educação das Relações Étnico-raciais e para o Ensino de História e Cultura Afro-brasileira e Africana .......... 49

2.3 A proposta da Lei 10.639/03 no contexto prático Descolonização curricular? ................................................ 51

2.4 Relações Raciais e Educação Intercultural: aproximações .... 58 
3 Procedimentos metodológicos

3.1 A chegada no campo da pesquisa - Escola Resgatando a Cultura

3.2 Estratégias metodológicas 76

3.2.1 Análise de documentos 76

3.2.2 Observações 80

3.2.3 Entrevistas

4 A Lei 10.639/03 na Escola Resgatando a Cultura: Cenas do cotidiano, atores, ações e contradições

4.1 A literatura como um caminho possível

4.2 Identidade e representação

4.2.1 Por que falarmos de raça?

4.2.2 Empoderamento e representatividade: "quando a gente pedia pra se desenhar, as crianças negras se desenhavam loiras".

4.2.3 A capoeira e a Lei 10.639/03: resistência e resgate 106

4.3 Limites para a implementação da Lei 10.639/03 110

4.3.1 "A gente fica acostumado com tudo pronto num "modelinho" para entregar pros alunos" - materiais didáticos: entre a falta e o costume

4.3.2 Religiosidade: um ponto de tensão

4.3.3 Formação dos professores

5 A Lei 10.639/03, a Educação Intercultural e a Escola Resgatando a Cultura

5.1 A instituição escolar: novos desafios

5.2 Perspectiva Intercultural: origens

5.3 Lei 10.639/03: limites e possibilidades para o diálogo intercultural

6 Considerações Finais

7 Referências bibliográficas 


\section{Lista de llustrações}

Figura 1 - Gráfico 1: Desigualdade de raça e gênero no Brasil ..... 51

Figura 2 - Mural do ano de 2008 com o título do projeto inicial ...... 68

Figura 3 - Apresentação da banda Afro-reggae que foi convidada a participar do Projeto, a partir de oficinas de percussão ............................................................. 68

Figura 4 - Os alunos prestigiando a banda e outras apresentações do projeto bimestral ............................. 69

Figura 5 - Alunos do $3^{\circ}$ ano encenando a história Menina Bonita do Laço de Fita ........................................................... 69

Figura 6 - Encenação da história Menina Bonita do Laço de Fita .. 70

Figura 7 - Apresentação de Capoeira com alunos/as e comunidade escolar ................................................ 72

Figura 8 - $\quad$ Apresentação do Grupo de percussão ………………... 72

Figura 9 - Apresentação de dança afro ....................................... 73

Figura 10 - Apresentação de alunos/as e de materiais no Projeto Literatura e Africanidades promovido pela Rede Municipal ....................................................... $\quad 74$

Figura 11 - Atividade sobre o conto africano Quianda e Quicimbe .. 93

Figura 12 - Exposição de livros ................................................... 93

Figura 13 - Cartaz de atividades sobre a leitura de Aguemon: um mito yourubá da criação do mundo ............................... 95

Figura 14 - Exposição do trabalho "Não deixe sua cor passar em branco" sobre identidade ............................................ 104

Figura 15 - Trabalhos expostos .............................................. 104

Figura 16 - Tela confeccionada pelas crianças representando o

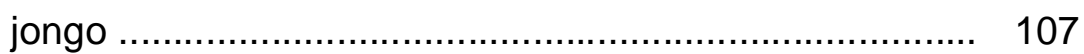

Figura 17 - Desenhos que representam a capoeira ….................... 108 


\title{
Lista de abreviaturas
}

\author{
ANPED - Associação Nacional \\ CNE - Conselho Nacional de Educação \\ DCN - Diretrizes Curriculares Nacionais \\ DEM - Partido dos Democráticos \\ FNB - Frente Negra Brasileira \\ GECEC- Grupo de Estudos Sobre Cultura (s), Educação e Escola. \\ IBGE - Instituto Brasileiro de Geografia e Estatística \\ IPEA - Instituto de Pesquisa Econômica Aplicada \\ LDBEN - Lei de Diretrizes e Bases da Educação Nacional \\ MNU - Movimento Negro Unificado \\ PUC - Pontifícia Universidade Católica \\ PT - Partido dos Trabalhadores \\ RJ - Rio de Janeiro \\ SECADI - Secretaria de Educação Continuada, Alfabetização, Diversidade e \\ Inclusão \\ SME - Secretaria Municipal de Educação \\ SEMED - Secretaria Municipal de Educação \\ SEPPIR - Secretaria de Políticas de Promoção da Igualdade Racial \\ TEN - Teatro Experimental do Negro \\ UFRRJ - Universidade Federal Rural do Rio de Janeiro
}

